\title{
Large-area electron beam irradiation for surface polishing of cast titanium
}

\author{
Junko TOKUNAGA, Tetsuya KOJIMA, Soichiro KINUTA, Kazumichi WAKABAYASHI, Takashi NAKAMURA, \\ Hirofumi YATANI and Taiji SOHMURA \\ Division of Oral Maxillofacial Regeneration, Graduate School of Dentistry, Osaka University, 1-8 Yamadaoka, Suita, Osaka 565-0871, Japan \\ Corresponding author, Junko TOKUNAGA; E-mail: j-toku@dent.osaka-u.ac.jp
}

\begin{abstract}
Cast titanium is a known hard-to-polish material, and its final polishing step is a perpetual challenge. The best way to tackle this challenge lies in automatic and non-mechanical polishing methods. Against this background, the suitability of large-area electron beam (EB) irradiation was examined in this study. In parallel, the optimum condition for efficient surface polishing was investigated. Cast titanium specimens were prepared, whereby their surface glossiness, surface roughness, and corrosion resistance were measured before and after EB irradiation. After EB irradiation, favorable results were observed: the cast titanium surface became smooth, the glossiness increased, and corrosion resistance was enhanced. These results were attributed to the low heat conductivity of titanium. With mechanical polishing, this property results in temperature rise and burnout reaction of the titanium surface with oxygen and the abrasives. However, during EB irradiation, the low heat conductivity of titanium was an advantage in raising the surface temperature to the melting point, such that a smooth surface was yielded after solidification. Based on the results obtained, automatic polishing by EB seemed to be a suitable polishing method for metal frameworks of removable dentures, and an efficient one too by saving time and effort.
\end{abstract}

Keywords: Electron beam, Polish, Titanium

Received Oct 15, 2008: Accepted Apl 2, 2009

\section{INTRODUCTION}

Polishing is the final step in the fabrication process of dental prostheses. The final polishing step is important and indispensable for two-fold reasons: to reduce the metallic taste or "battery feeling" in the mouth and to prevent discoloration and surface degradation caused by corrosion of the prostheses ${ }^{1,2)}$. However, polishing by hand or by mechanical polishing, which are the generally used manual operation methods, are timeconsuming and inefficient.

In particular, the mechanical polishing of cast titanium poses a great challenge due to the latter's high oxygen affinity and low thermal conductivity. A local increase in temperature causes discoloration of the polished surface, such that it becomes difficult to achieve high glossiness. Moreover, the polishing of cast titanium dentures is a very time-consuming procedure. Since polishing is the final process, it would mean that materials and time are wasted if polishing fails. Therefore, it is imperative that an advanced alternative method be developed to polish the metal frameworks of prostheses, especially cast titanium ones ${ }^{3-6)}$.

An identified promising alternative is polishing by large-area electron beam (EB) irradiation. Currently, the large-area electron beam (EB) irradiation equipment is used in the industrial field to polish metal molds. This equipment allows wide-area irradiation of up to $10 \mathrm{~cm}$ in diameter using a wire brush-like cathode - a feature considered to be more advantageous when compared with the conventional focused electron beam irradiation method. In terms of irradiation effects, improvements in surface smoothness and corrosion resistance after irradiation were reported $^{7-10)}$. Therefore, if this equipment were applicable to the polishing of dental prostheses, an improvement in polishing efficiency is an expectable outcome, especially for titanium dentures.

In parallel with investigating if EB irradiation is applicable to the polishing of cast titanium, the optimum condition for EB irradiation of cast titanium was also examined in this study. In light of these objectives, surface glossiness, surface roughness, and corrosion resistance after EB irradiation were measured and the effect of EB irradiation evaluated.

\section{MATERIALS AND METHODS}

\section{EB irradiation equipment}

Figure 1 shows the EB irradiation equipment (CRS 100, Nagata Seiki Co., Niigata, Japan) used in this study and a schematic diagram of the inside of the chamber. The principle of EB irradiation process is as follows. First, a magnetic field was generated using a solenoid coil located on the outside of the chamber. When the magnetic field reached maximum intensity, a voltage pulse was applied to the anode. In the chamber, electrons were generated by the Penning effect and began to move toward the anode. When the plasma intensity reached a maximum, a pulse voltage was applied to the cathode, and electrons were accelerated by the high electric field. An electron beam with a high energy density was then irradiated onto the workpiece surface.

The irradiation conditions as recommended by the manufacturer and the energy density and pulse duration employed for this study are as follows: acceleration voltage: $25 \mathrm{kV}$; anode voltage: $4.5 \mathrm{kV}$; solenoid voltage: $1.5 \mathrm{kV}$; argon gas pressure: $0.05 \mathrm{~Pa}$; distance to workpiece from the beam gun: $175 \mathrm{~mm}$; 


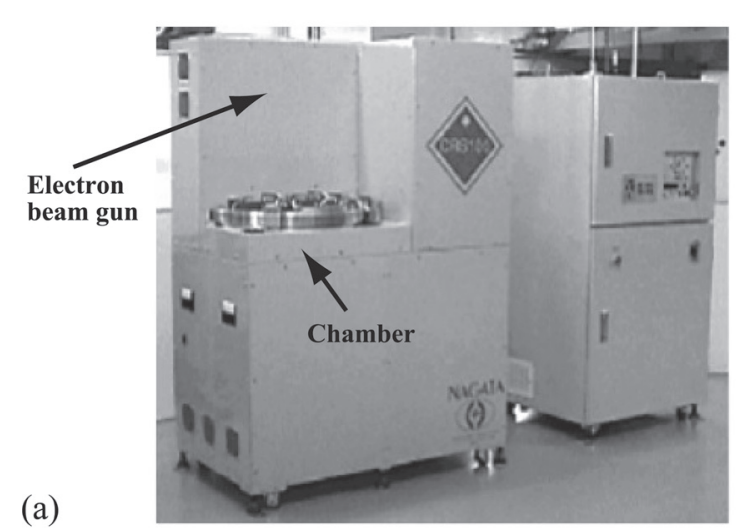

(a)

(b)

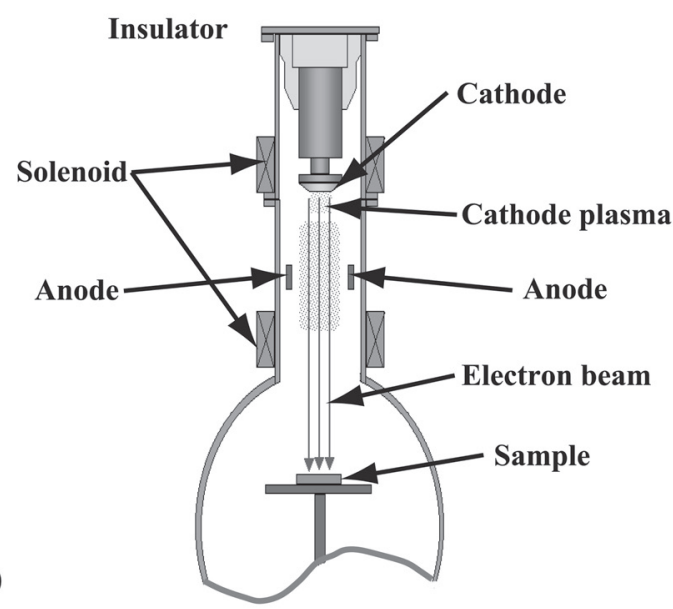

Fig. 1 (a) EB irradiation equipment CRS-100 (Nagata Seiki).

(b) Schematic diagram of the inside of the chamber.

energy density: $5.0 \mathrm{~J} / \mathrm{cm}^{2}$ per pulse; and pulse duration: $2-3 \mu \mathrm{s}$.

\section{Specimen preparation}

Pure titanium (JIS-Japanese Industrial Standard type 3, Kobelco Research Institute, Kobe, Japan) was cast into rectangular plate specimens with dimensions of 10 $\mathrm{mm} \times 15 \mathrm{~mm} \times 1.4 \mathrm{~mm}$. A plasma arc casting machine (EZ-titan, Wada Precision Dental Lab., Osaka, Japan) and phosphate-bonded investment molds (Super vest, Okazaki, Osaka, Japan) were used for casting. At a pressure of $4.0 \mathrm{MPa}$, the cast specimens were blasted by glass beads (Shofu, Kyoto, Japan) with an average particle size of $125 \mu \mathrm{m}$ that were dipped in nitrichydrofluoric acid solution (Horoclean MF-R, Hokurikuroka, Fukui, Japan) for 5-10 seconds. The purpose of doing so was to remove the oxidized layer on the surfaces of the specimens. After which, the cast specimens were randomly divided into two test groups as described below:

- Group 1: Specimens were subjected to EB irradiation at varying numbers of irradiation pulses - 20, 50, or 80 pulses - in order to determine the optimum condition for polishing.

- Group 2: Control specimens which were handpolished. The surfaces of cast titanium specimens were polished by conventional mechanical polishing using a micromotor engine with a carborundum point (Carborundum Point CA No. 13, Shofu, Kyoto, Japan) for 30 seconds, and then with a vinyl wheel (clever wheel, Okamotoshiken, Osaka, Japan) for 2 minutes.

\section{Examination of characteristics before and after EB} irradiation

1. Surface glossiness

Surface glossiness (Gs) was measured five times per specimen by a glossiness meter (Multi-Gross 268, Konica Minolta, Tokyo, Japan), and the average value was obtained according to ASTM D 523-67 $7^{11} \quad(n=5)$. The measurement area was $10 \mathrm{~mm} \times 10 \mathrm{~mm}$, and the incident light angle was 20 degrees $^{6}$.

2. Surface roughness

Surface roughness (Ra: arithmetical mean roughness) was measured five times per specimen with a transverse length of $4 \mathrm{~mm}$ by a surface roughness meter (Surfcorder SE1700a, Kosaka Lab., Tokyo, Japan) $(n=5)$.

3. Microstructural observation

The morphologies of the specimen surface and its crosssectional surface were observed using an SEM (JSM6390, JEOL, Tokyo, Japan). To compare the external surfaces of the same specimen before and after EB irradiation, half of each specimen was masked with copper plate before irradiation.

To observe the effect of EB irradiation inside the specimen, a cross-section of the specimen was obtained without plastic deformation. This was done by cutting the EB-irradiated side of the specimen from the nonirradiated side using a diamond disk. In this case, a thickness of approximately $0.5 \mathrm{~mm}$ of the irradiated surface was left uncut. The specimen was then dipped into liquid nitrogen and fractured in a brittle manner without plastic deformation. Finally, the cross-section of the specimen was irradiated with 80 pulses and observed using the SEM.

4. X-ray diffractometry (XRD)

The change in crystalline structure on the specimen surface after EB irradiation was examined by X-ray diffraction (RINT2100, Rigaku, Tokyo, Japan) with Cu$\mathrm{K} \alpha$ radiation generated at $40 \mathrm{kV}$ and $30 \mathrm{~mA}$.

5. Corrosion resistance

The corrosion resistance of the specimen before and after EB irradiation was evaluated by an immersion test in nitric-hydrofluoric acid solution and by anodic polarization measurement in $1.0 \% \mathrm{NaCl}$ solution.

5a. Immersion test

Four specimens of each condition - EB-irradiated with 80 pulses, hand-polished as a control, or polished with a buffing wheel — were dipped in nitric-hydrofluoric acid solution (Horoclean MF-R, Hokurikuroka Co. Ltd., 
Fukui, Japan) for 0, 2, 4, 6, and 8 seconds. After immersion, the surface glossiness of each condition was measured.

5b. Anodic polarization measurement

The initial resting potential at 30 minutes after immersion in $1.0 \% \mathrm{NaCl}$ solution at $37^{\circ} \mathrm{C}$ was measured $(n=4)$. Then, potentiodynamic anodic polarization measurements were performed under the following conditions: saturated calomel reference electrode; platinum counter electrode; and electrolyte solution of $1.0 \% \mathrm{NaCl}$ solution at $37^{\circ} \mathrm{C}$. The $\mathrm{NaCl}$ solution was aerated with argon gas for 30 minutes in order to prevent cathodic reaction from occurring due to dissolved oxygen in the solution. Measurements were carried out using a standard voltammetry tool (HSV100, Hokuto Denko, Tokyo, Japan), and potential was scanned from resting potential to $2.0 \mathrm{~V}$ at a rate of 0.5 $\mathrm{mV} / \mathrm{s}$. Current densities at a potential of $1.0 \mathrm{~V}$ were determined from anodic polarization curves ${ }^{12-14)}$.

\section{Statistical analysis}

For each test group in this study, the mean values of surface glossiness and surface roughness were calculated and the results statistically analyzed by oneway ANOVA and Tukey's multiple comparison test. Significance level was set at $\alpha=0.05$.

\section{RESULTS}

\section{Surface glossiness and roughness}

Figure 2 shows the surface glossiness and roughness results with respect to the number of EB irradiation pulses. Before EB irradiation, surface glossiness was $4.1 \mathrm{Gs}$ and surface roughness was $2.34 \mu \mathrm{m}$. After 20 pulses of EB irradiation, surface glossiness increased drastically to $154 \mathrm{Gs}$ and almost became saturated as

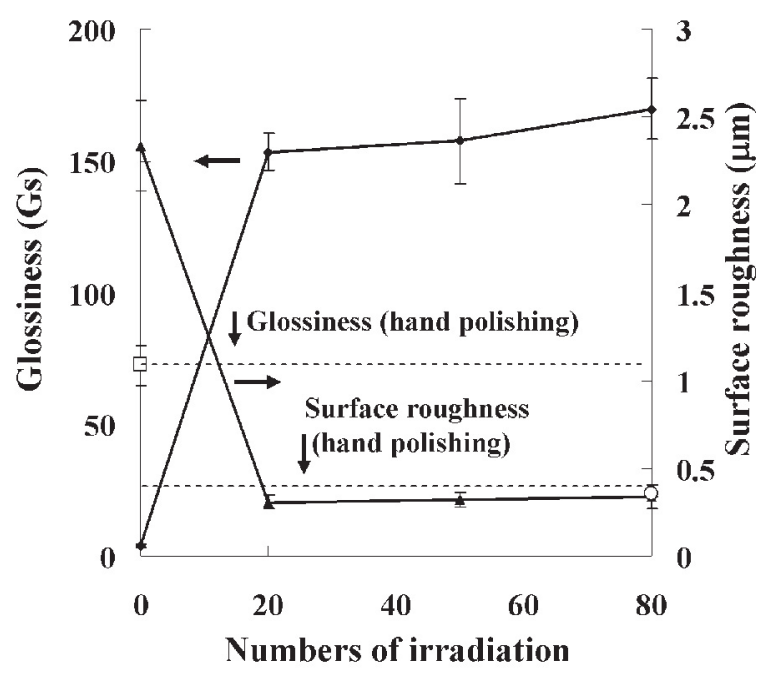

Fig. 2 Changes of glossiness and surface roughness with respect to the number of $\mathrm{EB}$ irradiation pulses. The glossiness and surface roughness of the handpolished specimen are shown by the dotted line. the number of irradiation pulses increased. With the increase in surface glossiness, surface roughness decreased dramatically to $0.31 \mu \mathrm{m}$ after 20 pulses of EB irradiation. For the hand-polished control group, surface glossiness was $72 \mathrm{Gs}$ and surface roughness was $0.35 \mu \mathrm{m}$. Therefore, upon comparing with the control group, surface glossiness was indeed improved by EB irradiation.

\section{Microstructural observation}

Figure 3(a) shows the SEM images of the surface morphologies according to the different numbers of EB

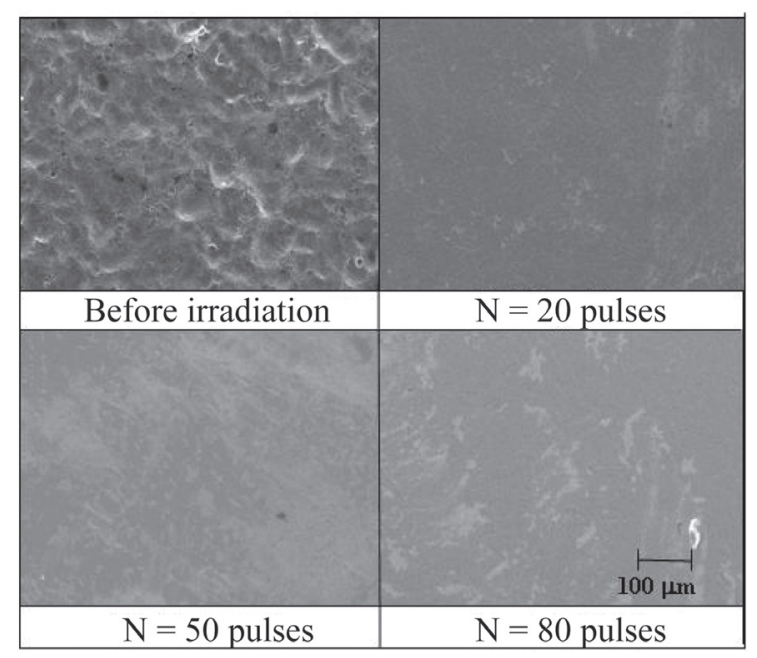

(b)

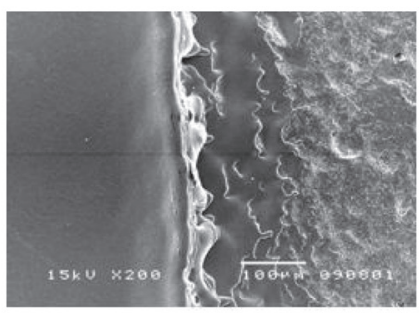

(c)

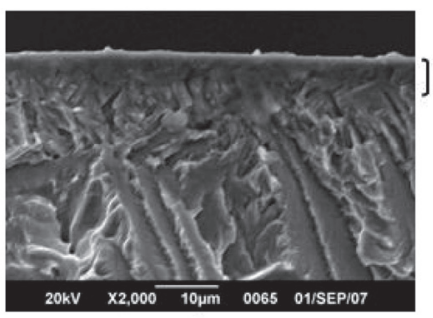

Fig. 3 (a) SEM images of the EB-irradiated surfaces with increasing number of $\mathrm{EB}$ irradiation pulses.

(b) SEM image of the surface morphology before and after EB irradiation: right half surface was masked by a copper plate while left half surface was irradiated with 30 pulses.

(c) SEM image of the cross-section of the specimen irradiated with 80 pulses. 
irradiation pulses. The surface, which was jagged before EB irradiation, became smooth after 20 pulses of irradiation. Similar images of smooth surfaces were also observed as the number of irradiation pulses increased. The typical change in the surface morphology of the same specimen after EB irradiation is shown in Fig. 3(b), where the right half surface was masked by copper plate and the left half surface irradiated with 30 pulses. The effect of EB irradiation on surface smoothing was clearly shown in this specimen.

Figure 3(c) shows the SEM image of the crosssection of the specimen irradiated with 80 pulses. A smooth surface layer of approximately $7 \mu \mathrm{m}$ in depth was observed, but the inside of the specimen remained a dendrite cast structure. The surface layer was presumed to be melted by EB irradiation and then solidified.

\section{$X$-ray diffraction profile}

Figure 4 shows the X-ray diffraction profiles of the specimen before and after EB irradiation. $\alpha$-titanium peaks could be traced at the positions of $2 \theta=35.2,38.3$, 40.2, 52.9. No other peaks except $\alpha$-titanium were observed in the profiles for the different numbers of irradiation pulses, and the peak positions did not change after irradiation. However, the intensity ratios of $\mathrm{Ti}$ (101) peaks were somewhat different. This suggested that the crystalline plane which emerged at the surface of the specimen was altered by melting and the subsequent solidification.

\section{Corrosion resistance}

\section{Immersion test}

As shown by the solid rectangular marks in Fig. 5(a), surface glossiness of the EB-irradiated group (80 pulses) decreased from $185 \mathrm{Gs}$ to $152 \mathrm{Gs}$ after immersion in nitric-hydrofluoric acid for 2 seconds. However, after a further immersion for 8 seconds, a glossiness of over $122 \mathrm{Gs}$ was achieved. As for the hand-polished control group, the original glossiness was as low as approximately $75 \mathrm{Gs}$ and decreased to approximately $50 \mathrm{Gs}$ after immersion. Figure 5(b) shows the photographs of both groups of specimens after immersion for 8 seconds. With the hand-polished specimen, etched crystalline structure by the acid solution was clearly observed, whereas less etching was observed in the EB-irradiated specimen.

2. Anodic polarization measurement

Figure 6(a) shows the resting potential values with respect to the number of EB irradiation pulses. Before EB irradiation, the resting potential was $0.03 \mathrm{~V}$. After 20 pulses of irradiation, the resting potential increased to $0.12 \mathrm{~V}$ and thereafter increased with the number of irradiation pulses. As for the hand-polished control specimen, the resting potential was $0.07 \mathrm{~V}$. Therefore, with increase in resting potential after EB irradiation of up to 80 pulses, the surface corrosion resistance of cast titanium also improved.

Figure 6(b) shows the anodic polarization curves of

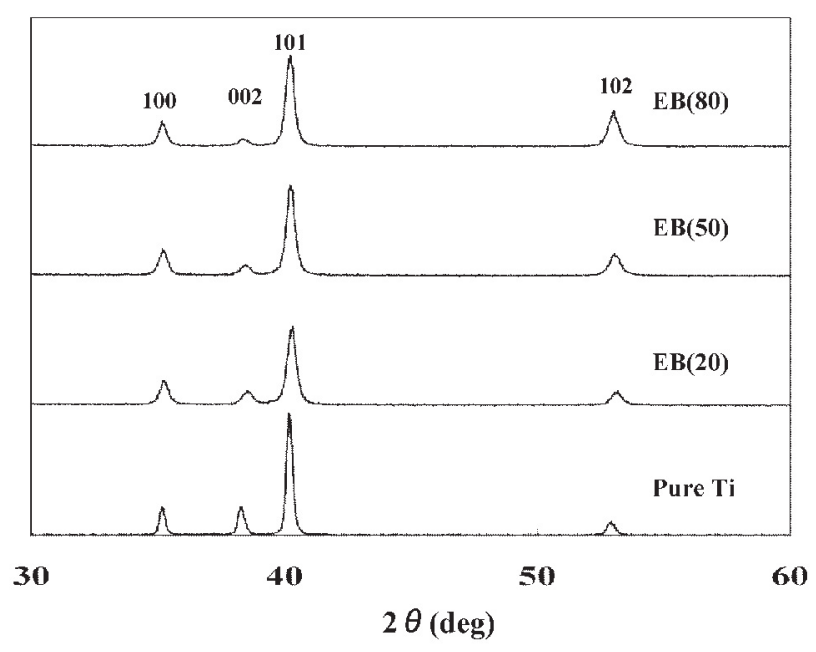

Fig. 4 X-ray diffraction profiles of the specimen before and after EB irradiation.

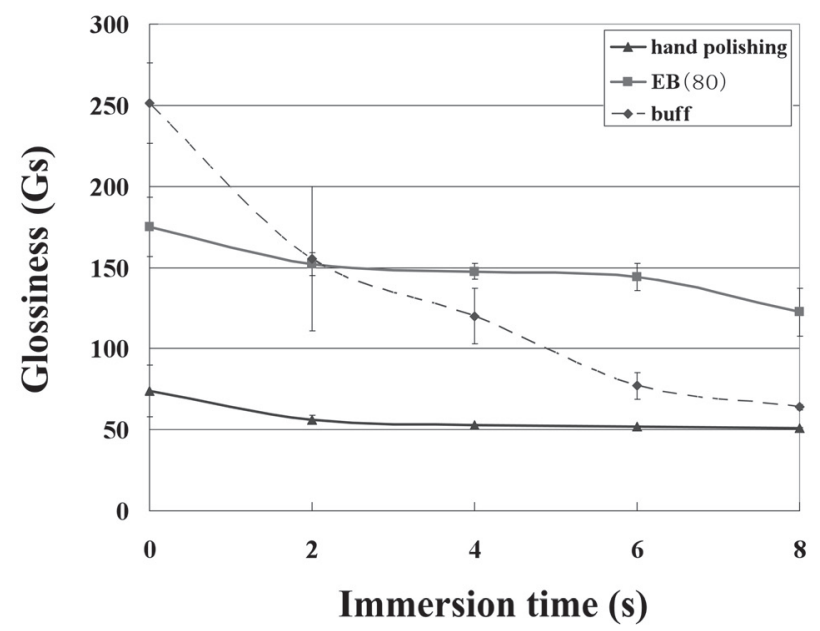

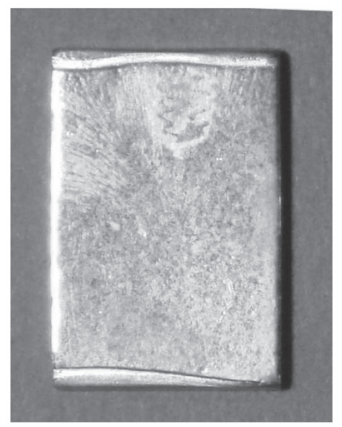

EB (80)

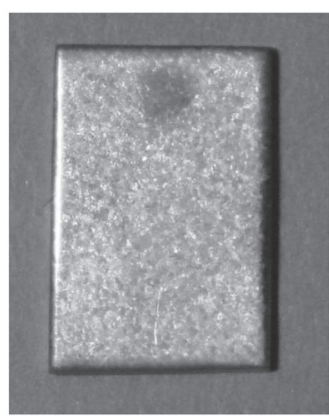

Hand polishing
Fig. 5 (a) Changes in glossiness by immersion test in nitric-hydrofluoric solution for these specimens: EB-irradiated with 80 pulses, hand-polished, and buff-polished.

(b) Photographs of specimens EB-irradiated with 80 pulses and hand-polished after immersion in nitric-hydrofluoric solution for 8 seconds. 


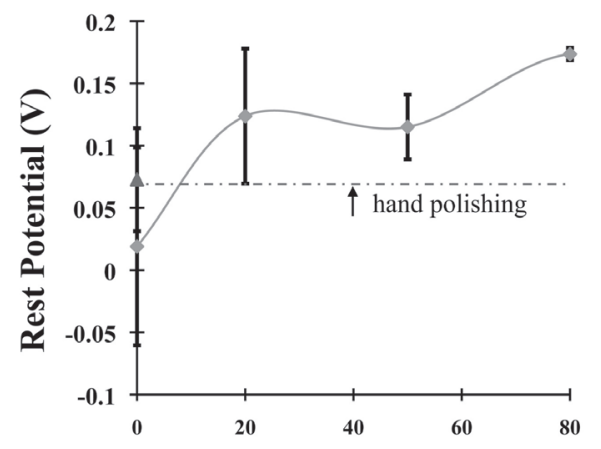

(a) Numbers of irradiation

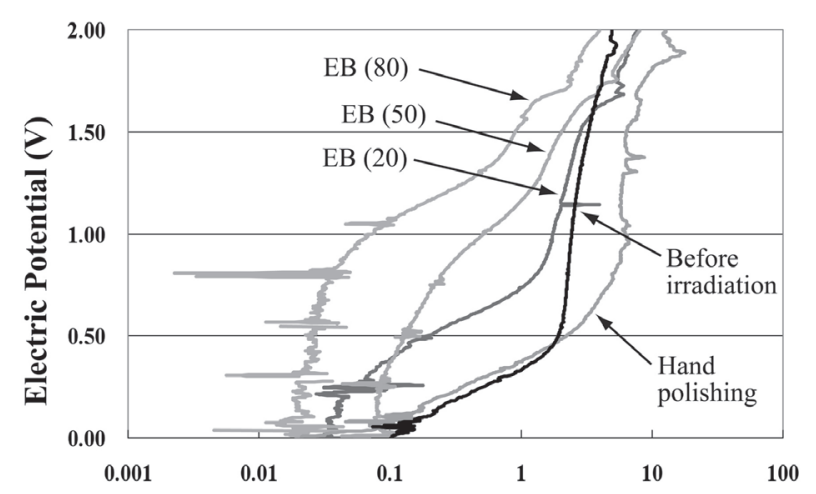

(b)

Current Density $\left(\mu \mathrm{A} / \mathrm{cm}^{2}\right)$

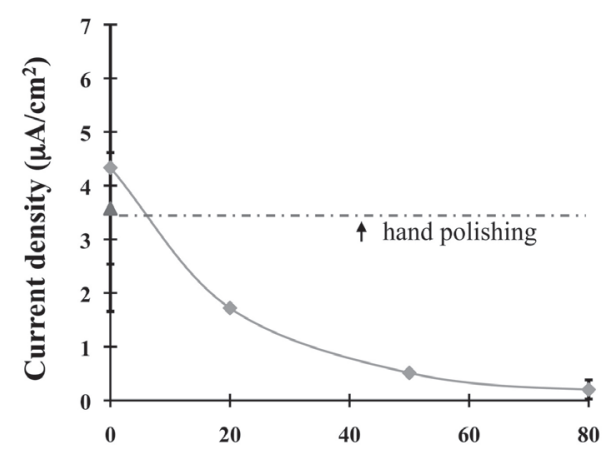

(c) Numbers of irradiation

Fig. 6 (a) Change of resting potential in $1 \% \mathrm{NaCl}$ solution with respect to the number of $\mathrm{EB}$ irradiation pulses. Resting potential of handpolished specimen is shown by the dotted line.

(b) Anodic polarization curves of specimens in $1 \%$ $\mathrm{NaCl}$ solution before $\mathrm{EB}$ irradiation and after being irradiated with 20,50 , and 80 pulses or hand-polished.

(c) Change of current density of anodic polarization measurement at $1.0 \mathrm{~V}$ with respect to the number of EB irradiation pulses. Current density of hand-polished specimen is shown by the dotted line. the EB-irradiated group for the different numbers of irradiation pulses. Many noises were observed in the potential vs. current density curves due to a very low current, which was so because of the small amount of dissolved titanium ions. Although some crossovers between curves were observed, there was nonetheless an apparent tendency for the current density to decrease with the number of EB pulses.

Figure 6(c) shows the current density at the electric potential of $1.0 \mathrm{~V}$. Before EB irradiation, the current density was $4.4 \mu \mathrm{A} / \mathrm{cm}^{2}$ whereas that of the hand-polished control specimen was $3.6 \mu \mathrm{A} / \mathrm{cm}^{2}$. As the number of EB irradiation pulses increased to 20, 50, and 80 pulses, a significant decrease in current density was observed when compared against the specimen before irradiation and the hand-polished specimen. Taken together, these results showed that EB irradiation resulted in an increase in the corrosion resistance of cast titanium.

\section{DISCUSSION}

In the present study, we investigated the potential application of EB irradiation for the final polishing of a representative difficult-to-polish metal, cast titanium. The difficulty in polishing cast titanium mechanically stems from its inherent properties: high surface hardness and high chemical reactivity with oxygen and investment materials. Furthermore, its low thermal conductivity easily results in temperature increase, thereby leading to burnout reactions with abrasives such as alumina or carborundum. Consequently, the surface glossiness of cast titanium is reduced by these reactions and the surface is discolored by oxidation. To address and overcome these problems related to the mechanical polishing of cast titanium, the possibility of non-mechanical polishing by $\mathrm{EB}^{15)}$ was investigated in the present study.

In this experiment, the irradiation conditions of the $\mathrm{EB}$ equipment, such as the acceleration voltage, anodic voltage, and argon gas pressure, were applied according to the recommended settings for metal mold polishing by the manufacturer. In the preliminary experiment, the number of irradiation pulses was found to be the most influential parameter in improving surface glossiness. On this premise, we examined the effect of the number of irradiation pulses on surface glossiness, surface roughness, and the corrosion resistance of cast titanium.

Sufficient increase in surface glossiness, in conjunction with sufficient reduction in surface roughness, were obtained with 20 pulses of $\mathrm{EB}$ irradiation $^{3)}$. By further increasing the number of irradiation pulses, surface glossiness and surface roughness almost reached their saturation levels, as shown in Fig. 2. Therefore, 20 irradiation pulses seemed to be sufficient for achieving an acceptable level of surface glossiness for dental prostheses.

The time required for 20 pulses of EB irradiation was approximately 15 minutes. While the net time 
required for one irradiation pulse took only $2-3 \mu \mathrm{s}$, the total required time - which encompassed the time needed for sample setting in the EB equipment, gas change, and stabilization of the argon gas atmosphere for further irradiations - was 15 minutes. In the dental laboratory, mechanical polishing by hand for a titanium plate of a removable denture usually requires approximately 30 minutes. In comparison, application of EB irradiation presented more advantages: automatic polishing that would contribute to reduced working time and human effort, especially for large prostheses such as dentures.

The cross-sectional SEM image after EB irradiation in Fig. 3(c) shows that the depth of metallographic change was approximately up to $7 \mu \mathrm{m}$ from the surface. This suggested that the surface was dissolved once by EB irradiation and then solidified. However, in the XRD profiles shown in Fig. 4, no significant changes or modification in the profile were observed, such as the appearance of a new peak, or peak shift and half-peak width. In previous reports ${ }^{16,17)}$, the temperature of the metal surface was reported to increase to $2,000^{\circ} \mathrm{C}$ by EB irradiation. Since the melting point of titanium is $1,668^{\circ} \mathrm{C}$, the cast titanium surface was most probably melted by EB irradiation in this study. Furthermore, the heat conductivity of titanium is $21.9 \mathrm{~W} / \mathrm{m} \cdot \mathrm{K}$, which is equivalent to $1 / 15$ that of gold and 1/20 that of silver. This meant that the heat energy introduced by EB irradiation had easily accumulated on the cast titanium surface. This heat energy then effectively melted the titanium surface, followed by smoothing the surface after solidification ${ }^{18)}$. During mechanical hand polishing, the heat accumulated during polishing causes a burnout reaction with abrasives, which works adversely against increasing glossiness. However, in the context of EB irradiation, the low heat conductivity of titanium was an advantage; vice versa, EB seemed to be a suitable method for titanium polishing.

We also examined the effect of EB irradiation in $\mathrm{Au}-\mathrm{Ag}-\mathrm{Pd}$ alloys and found that more irradiation pulses were required in order to achieve acceptable glossiness - although the melting point of Au-Ag-Pd alloy is approximately $970^{\circ} \mathrm{C}$, which is far lower than that of titanium $^{19,20)}$. The reason for the reduced effectiveness of $\mathrm{EB}$ irradiation in $\mathrm{Au}-\mathrm{Ag}-\mathrm{Pd}$ alloy as compared to titanium is the higher heat conductivity of Au-Ag-Pd alloy, which is approximately 25 times higher than that of titanium.

Another advantage of EB irradiation over handpolishing was manifested through the increased corrosion resistance. After the immersion test in the strong nitric-hydrofluoric acid solution for 8 seconds, the surface glossiness of the irradiated specimen decreased from 185 Gs to 122 Gs. On the other hand, with the hand-polished control specimen, surface glossiness decreased from $75 \mathrm{Gs}$ to $51 \mathrm{Gs}^{8)}$. Since the initial glossiness of this specimen was too low, additional polishing by a buffing wheel was performed until a glossiness of $250 \mathrm{Gs}$ was achieved. A supplementary immersion test in nitric-hydrofluoric acid solution was then performed. The results are shown in Fig. 5 by the dotted line. Surface glossiness decreased rapidly from $250 \mathrm{Gs}$ to $60 \mathrm{Gs}$ after immersion for 8 seconds. In other words, the corrosion resistance of the EB-irradiated surface was still markedly higher than that of the mechanically polished surface.

In concurrence with the corrosion resistance results demonstrated through the pickling of cast titanium in nitric-hydrofluoric acid solution, the resting potential and current density obtained via anodic polarization measurement also showed the same tendency. As shown in Fig. 6, corrosion resistance seemed to be improved by increasing the number of irradiation pulses. Taking together the corrosion resistance results shown in Figs. 5 and 6, it could be seen that apart from not causing any intergranular corrosion, EB irradiation caused a uniform surface to be formed. Conversely, mechanical polishing induces intergranular corrosion, thereby causing the unstable current density of anodic polarization to increase.

It has been reported that corrosion resistance improvement occurred due to the formation of an amorphous phase by EB irradiation ${ }^{7,16)}$. In the present study, however, no such additional phase was detected, even when examined using thin film X-ray diffraction. Echoing the conclusion drawn from the anodic polarization results in Fig. 6, EB irradiation led to improved corrosion resistance because it induced the formation of a uniform strain- and contamination-free surface.

The purpose of this study was to examine the suitability and applicability of EB for the polishing of cast titanium, and findings of this study were affirmatively positive. However, to apply EB to the polishing of dental prostheses in a clinical setting, a number of practical problems remained unresolved. First, the specimens used in the present study were limited to flat plates. This meant that the effect of EB on tilted or curved surfaces remained to be examined. According to Okada et al., it was possible to polish surfaces tilted by almost $90^{\circ}$ by EB irradiation ${ }^{10)}$. Upon obtaining the results of $\mathrm{EB}$ applicability on tilted or curved surfaces in future studies, these results would be translated into practical applications for dental prostheses.

\section{ACKNOWLEDGMENTS}

The authors would like to thank Dr. Kensuke Uemura and Dr. Purwadi Raharjo, as well as the other staff members of Nagata Seiki Co. Ltd., for their support toward this EB experiment and for their time and availability to engage in invaluable discussions.

The authors would like to thank Yujiro Nomura, Masayoshi Hashimoto, and Yoichi Kumazawa of Wada Precision Dental Laboratories Co., Ltd. for their support for specimen preparation and for engaging in discussions on dental applications using this equipment. 


\section{REFERENCES}

1) Quirynen M, Marechal M, Busscher HJ, Weerkamp AH, Darius PL, van Steenberghe D. The influence of surface free energy and surface roughness on early plaque formation. An in vivo study in man. J Clin Periodontol 1990; 17: 138-144.

2) Rimondini L, Fare S, Brambilla E, Felloni A, Consonni C, Brossa F, Carrassi A. The effect of surface roughness on early in vivo plaque colonization on titanium. J Periodontol 1997; 68: 556-562.

3) Hirata T, Nakamura T, Takashima F, Maruyama T, Taira M, Takahashi J. Studies on polishing of Ti and Ag-Pd-Cu$\mathrm{Au}$ alloy with five dental abrasives. J Oral Rehabil 2001; 28: 773-777.

4) Miyakawa O. Reactivity of titanium with abrasive materials and its polishing. J Jpn Prosthodont Soc 1998; 42: 540-546.

5) Shimakura M, Yamamoto M, Nakajima K, Yoshida N. Application of a centrifugal shooting type polishing system to polish pure titanium. Dent Mater J 2000; 19: 405-412.

6) Ohkubo C, Hosoi T, Ford JP, Watanabe I. Effect of surface reaction layer on grindability of cast titanium alloys. Dent Mater 2006; 22: 268-274.

7) Purwadi R, Wada H, Nomura Y, Ozur GE, Proskurovsky DI, Rotshtein VP, Uemura K. Pulsed electron beam technology for surface modification of dental materials. Proc. of 6th International Conference on Modification of Materials with Particle Beams and Plasma Flows 2002; 679682.

8) Uno Y, Okada A. Surface modification of EDMed surface by electron beam irradiation (<Special Issue $>$ Novel development of electrical discharge machining). J Jap Soc Prec Eng 2005; 71: 553-556.

9) Uno Y, Okada A, Uemura K, Purwadi R, Furukawa T, Karato K. High-efficiency finishing process for metal mold by large-area electron beam irradiation. Prec Eng 2005; 29: 449-455.

10) Okada A, Uno Y, Nishina N, Uemura K, Purwadi R, Sano $\mathrm{S}, \mathrm{Yu} \mathrm{Z}$. High efficiency surface finishing of metal mold by large-area electron beam irradiation (2nd Report) -
Smoothing of tilting surfaces and surface modification effect. J Jap Soc Prec Eng 2005; 71: 1399-1403.

11) Japanese Standards Association (established 1962). Methods of measurement for glossiness - JIS (Japanese Industrial Standard) Z 8741-1962.

12) Takahashi M, Kikuchi M, Takada Y, Okabe T, Okuno O. Electrochemical behavior of cast Ti-Ag alloys. Dent Mater J 2006; 25: 516-523.

13) Mimura H, Miyakawa Y. Electrochemical corrosion behavior of titanium castings. Part I: Effect of degree of surface polishing and kind of solution. J J Dent Mater 1996; 15: 283-295.

14) Mimura H, Miyakawa $Y$. Electrochemical corrosion behavior of titanium castings. Part 2: Effects of finishing treatments on the surface of the innermost structure. J J Dent Mater 1996; 15: 296-305.

15) Guilherme AS, Henriques GE, Zavanelli RA, Mesquita MF. Surface roughness and fatigue performance of commercially pure titanium and Ti-6Al-4V alloy after different polishing protocols. J Prosthet Dent 2005; 93: 378-385.

16) Pogrebnjak AD, Bratushka S, Boyko VI, Shamanin IV, Tsvintarnaya YV. A review of mixing processes in $\mathrm{Ta} / \mathrm{Fe}$ and $\mathrm{Mo} / \mathrm{Fe}$ systems treated by high current electron beams. Nucl Instr and Meth in Phys Res B 1998; 145: 373-390.

17) Proskurovsky DI, Rotshtein VP, Ozur GE. Use of low-energy high-current electron beams for surface treatment of materials. Surf Coat Technol 1997; 96: 117-122.

18) Akamatsu H, Azuma K, Fujiwara E, Yatsuzuka M. Nanocrystallization of pure titanium surface by intense pulsed ion beam irradiation. Jpn J Appl Phys 2002; 41: 399-404.

19) Tokunaga J, Kojima T, Sohmura T, Nomura $Y$, Kinuta $S$, Wakabayashi K, Mutobe Y, Nakamura T, Yatani H. Surface modification of dental alloy by electron-beam system (Part5): Effect on the crystallization of Au-Ag-Pd alloy. J J Dent Mater 2006; 25: 161.

20) Tokunaga J, Kojima T, Nomura Y, Kinuta S, Wakabayashi K, Mutobe Y, Nakamura T, Yatani H, Sohmura T. Surface modification of dental alloy by electron-beam system (Part 6): Microstructure changes of Au-Ag-Pd alloy surface. $\mathrm{J} \mathrm{J}$ Dent Mater 2006; 25: 342. 